\title{
The Relationship Research between the Internet Finance and Commercial Banks
}

\author{
Shengdong $\mathrm{Mu}^{\mathrm{a}}$, Yixiang Tian ${ }^{\mathrm{b}}, \mathrm{Li} \mathrm{Li}^{\mathrm{c}}$ \\ School of Management and Economics, University of Electronic Science and Technology of China, \\ Chengdu, 614100 China \\ amushengd@163.com, btianyx@uestc.edu.cn, ${ }^{c k}$ kylili075@163.com
}

\begin{abstract}
The rapid development of the Internet finance has brought great impact and challenge to traditional financial institutions; especially the commercial banks, the competitive game between Internet finance and commercial Banks are inevitable. But how the Internet finance influence commercial banks, which is more positive influence or negative influence, it is the bank's competitive overturn or mutual symbiosis, a clear answer still did not be given from the aspects of quantitative analysis, the relationship are studied between the two from the empirical perspective, especially the impact Internet finance on bank operating efficiency is a blank. This paper is based on the premise of limited rationality of the Internet finance and commercial Banks, by establishing the game payment matrix, analyzing the game problems of Internet finance and commercial Banks, and how the two constantly adjust their own strategy to deal with opposite selective strategy in the process of game in order to achieve the maximization of their own earnings.
\end{abstract}

Keywords: Internet finance; Commercial Banks; Game Payment Matrix.

\section{Introduction and Literature Summary}

Internet finance constantly carry out the traditional business of commercial Banks with much innovativeness, commercial Banks also constantly carry out business innovation to deal with the Internet finance, the commercial banks is faced with the great impact brought about by the Internet finance, which will inevitably take action, a fierce game between Internet financie and commercial Banks are inexorable.

The domestic and foreign research scholars have paid close attention to relationship between Internet finance and traditional commercial banks and have carried out much analysis. On the whole, these research have focused on model definition of Internet finance, impact Internet finance on the traditional banking, and qualitative analysis of banking countermeasures, such as Wan Jianhua (2012), Li Bo, Dong Liang, they expounded and analyzed specific mode of Internet finance, and put forward relevant policy suggestions; Gong Xiaolin(2013), Chen Haiqiang(2014), Feng Juanjuan(2013), Guo Tianyong, Meng Jiao(2013) analyzes Internet financial model and the influence on traditional banking, reveals the advantage and shortcoming of the commercial banks and Internet finance, put forward the development strategy of the banking industry; FDC (2009) pointed out that Internet finance can provide financial services to the people in the financial gap and reduce their time costs. Empirical analysis of Internet finance is less, it mainly concentrated on the Internet finance impact on the macroeconomic level, such as Grace, Jeremy, Kenny and Christine Zhen-Wei Qiang (2003) [p.204] stress the Internet financial is conducive to the formation of the capital, so as to promote economic growth; Jorgoisoii (2001) [9], Oliner and Sichel (2004), Jorgenson and Stiroh (2000) believe that the positive role of the Internet finance development are gradually obvious to economic growth; Wang Lifeng (2010) focuses on the development of the third-party payment, empirically analyze the influence of third-party payment on macro-economy. These research from the perspective of qualitative analysis research studied the relationship between Internet finance and commercial banks, it is generally believed that the Internet finance drive China's financial efficiency, trade structure, even the whole financial architecture is undergoing profound changes, the traditional financial institutions need to use introspection and development vision to deal with the rapid market change in order to achieve steady and rapid development in the competition coexistence of Internet age. 


\section{Establishment of Game Model}

Basic assumptions of model:

(1) The Internet finance and commercial banks are limited rational; they can keep learning and imitating the other's strategy;

(2) When the Internet finance and commercial banks do not cooperate with each other, they can choose to cooperate with the third party;

(3) Whether the Internet finance or commercial banks, when choosing cooperation with third party, its benefits are greater than their own action. The game payment matrix of Internet finance and commercial banks as shown in Table 1:

Table 1 Game payment matrix

\begin{tabular}{|c|c|c|c|}
\hline \multirow{4}{*}{ Internet } & \multicolumn{3}{|c|}{ Commercial banks } \\
\cline { 2 - 4 } Finance & & cooperation $(q)$ & competition $(1-q)$ \\
\cline { 2 - 4 } & $(p)$ & $r_{1}+\varphi \Delta r$ & $r_{1}+b_{1}-c_{1}$ \\
& cooperation & $r_{2}+(1-\varphi) \Delta r$ & $r_{2}+b_{2}-c_{2}$ \\
\cline { 2 - 4 } & $(1-p)$ & $r_{1}+b_{1}-c_{1}$ & $r_{1}$ \\
& $r_{2}+b_{2}-c_{2}$ & $r_{2}$ \\
\hline
\end{tabular}

In the table, $r_{1}, r_{2}$ are respectively represent their present own income of Internet finance and commercial banks, $\Delta r$ is the earnings increment when Internet finance commercial banks choose cooperation, $\varphi$ is the assignment weight of Internet finance on income increment, namely when the both sides cooperate, additional earnings of Internet financial earnings is $(1-\varphi) \Delta r$, at the moment, the gross earnings of Internet finance is $r_{2}+(1-\varphi) \Delta r$; and additional earnings of commercial banks is $(1-\varphi) \Delta r$, its gross earnings is $r_{1}+\varphi \Delta r$, when the Internet finance do not cooperate with commercial banks, and choose to cooperate with third parties, its earnings is $r_{1}+b_{1}-c_{1}$, and $b_{1}>c_{1}$, among them, $b_{1}, c_{1}$ are respectively the earnings and cost of Internet finance in cooperation with a third party; Likewise, when commercial banks do not cooperate with Internet finance and collaborate with third parties, its earnings is $r_{2}+b_{2}-c_{2}$, and $b_{2}>c_{2}$, among them, $b_{2}, c_{2}$ are respectively earnings and cost of the commercial banks in cooperation with third parties; Clearly, if $\mu_{1}<c_{1}$, Internet finance and commercial banks will not choose to cooperate with third parties.

Assuming that the probability of Internet finance in cooperation with commercial banks is $p$, the probability of taking competition is $1-p$; similarly, the probability of commercial bank in cooperation with Internet finance is $q$, the probability of taking competition is $1-q ; p$ and $q$ meet and comply standard normal distribution, which is $(p, q) \sim N(0,1)$.

\section{The Analysis of Game Model}

The final game results of Internet finance and commercial banks, which is mutual cooperation or competition, depends on the size of their expected earnings, when choosing the expected earnings of "cooperation" is greater than expected returns of "competition", it will choose the "cooperation" strategy, and vice versa.

The choice strategy analysis of Internet finance

According to the game payment matrix, expected earnings of the Internet finance can be calculated, when the Internet finance take "cooperation" strategy, the expected return is $R_{11}=q\left(r_{1}+\varphi \Delta r\right)+(1-q)\left(r_{1}+b_{1}-c_{1}\right)$, when the Internet finance take "competition" strategy, the expected return is $R_{12}=q\left(r_{1}+b_{1}-c_{1}\right)+(1-q) r_{1}$ :, assuming Internet finance take "cooperation" strategy, then need to meet $R_{11}>R_{12}$, that is $q\left(r_{1}+\varphi \Delta r\right)+(1-q)\left(r_{1}+b_{1}-c_{1}\right)>q\left(r_{1}+b_{1}-c_{1}\right)+(1-q) r_{1}$, which can get the conditions of Internet finance cooperating with third parties: when $c_{1}>b_{1}-\varphi(\Delta r)$, 
the expected earnings of Internet finance choosing cooperation is greater than expected earnings of choosing competition, at this time, "cooperation" strategy is the optimal strategy of the Internet finance, Internet finance will choose cooperation with commercial banks.

In the same way, if the cost of the Internet finance in cooperation with a third party meet the conditions, when $c_{1}<b_{1}-\varphi(\Delta r)$, the expected earnings of Internet finance choosing "competition" strategy is greater than the expected earnings when choosing "cooperation", the "competition" strategy is the Internet financial dominant strategy, Internet finance will choose to compete with commercial banks.

In fact, the Internet finance and commercial banks is not just a simple "competition" and "cooperation" problem, the "competition" and "cooperation" strategy needs to be considered at the same time, namely mixed strategy, the expected earnings of Internet finance under mixed strategy is as follows:

$$
R_{1}=p\left[q\left(r_{1}+\varphi \Delta r\right)+(1-q)\left(r_{1}+b_{1}-c_{1}\right)\right]+(1-p)\left[q\left(r_{1}+b_{1}-c_{1}\right)+(1-q) r_{1}\right]
$$

The Internet financial replicated dynamic equation is:

$$
F_{1}(p)=\frac{d p}{d t}=p(1-p)\left(R_{11}-R_{12}\right)=p(1-p)\left[q(r \Delta r)-2\left(b_{1}-c_{1}\right)+b_{1}-c_{1}\right]
$$

If $F_{1}(p)=0$, then $p=0, p=1, q=\frac{c_{1}-b_{1}}{\varphi \Delta r-2\left(b_{1}-c_{1}\right)}$ as a stable state point, it is known from the property of the evolutionary stable strategy, when $F_{1}^{\prime}\left(p^{*}\right)<0, p^{*}$ is the evolutionary stable strategy, namely when $q=\frac{c_{1}-b_{1}}{\varphi \Delta r-2\left(b_{1}-c_{1}\right)}$, when, $F_{1}(p)=0$, all $p$ are the steady state point at this time.

(1) when $0<q<1,0<q<\frac{c_{1}-b_{1}}{\varphi \Delta r-2\left(b_{1}-c_{1}\right)}<1$, if you want to meet $0<q<\frac{c_{1}-b_{1}}{\varphi \Delta r-2\left(b_{1}-c_{1}\right)}<1$, that is $b_{1}>c_{1}$, and $\varphi \Delta r<b_{1}-c_{1}$, provided assigned incremental earnings of the Internet finance in cooperation with commercial banks is less than the net income obtained in cooperation with third parties, Internet finance will choose cooperation with third parties. The phase diagram is as follows:

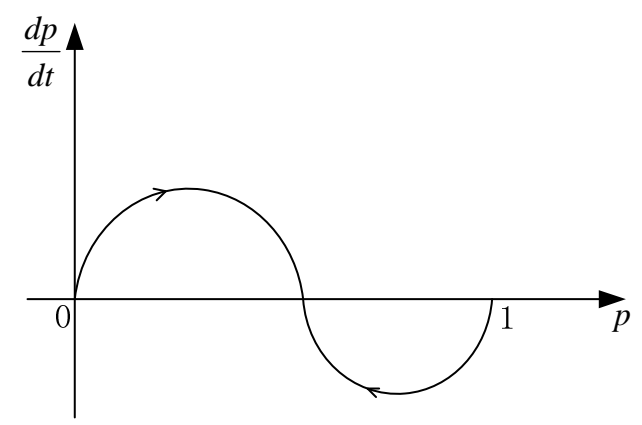

Fig.1 The $q=\frac{c_{1}-b_{1}}{\varphi \Delta r-2\left(b_{1}-c_{1}\right)}$ phase diagram

(2) when $q>\frac{c_{1}-b_{1}}{\varphi \Delta r-2\left(b_{1}-c_{1}\right)}, F_{1}^{\prime}(1)<0, p^{*}=1$ is the evolutionary stable strategy at this time, under Internet finance and commercial banks repeated game, when the probability of commercial banks choosing cooperation is more than $\frac{c_{1}-b_{1}}{\varphi \Delta r-2\left(b_{1}-c_{1}\right)}$, the Internet finance will choose cooperation with commercial banks. The phase diagram is as follows: 


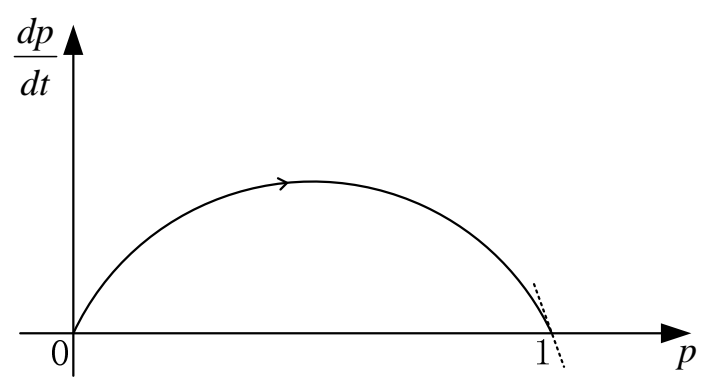

Fig.2 $q>\frac{c_{1}-b_{1}}{\varphi \Delta r-2\left(b_{1}-c_{1}\right)}$ phase diagram

(3) when $q<\frac{c_{1}-b_{1}}{\varphi \Delta r-2\left(b_{1}-c_{1}\right)}, F_{1}^{\prime}(1)<0, p^{*}=0$ is evolutionary stable strategy, under the Internet finance and commercial banks repeated game, when the probability of commercial Banks choosing cooperation is less than $\frac{c_{1}-b_{1}}{\varphi \Delta r-2\left(b_{1}-c_{1}\right)}$, the Internet finance will ultimately choose to compete with commercial banks. The phase diagram is as follows:

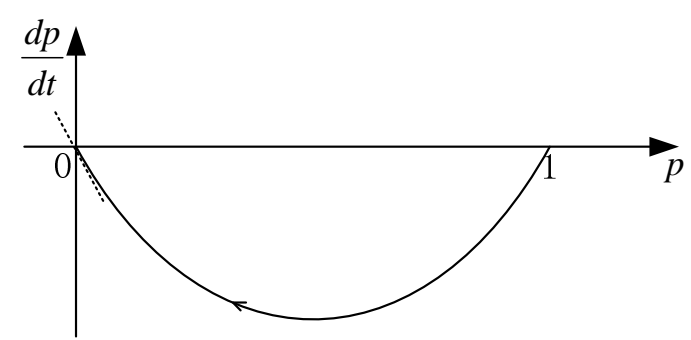

Fig.3 $q<\frac{c_{1}-b_{1}}{\varphi \Delta r-2\left(b_{1}-c_{1}\right)}$ phase diagram

(4) When $b_{1}>c_{1}$ and $\varphi \Delta r<2\left(b_{1}-c_{1}\right)$, namely the obtained earnings of Internet finance in cooperation with a third party institutions is more than the costs, and revenue increment of Internet finance in cooperation with commercial banks is less than the earning of Internet finance in cooperation with third parties, and it is 2 times more than cost variance, at this time, $\frac{c_{1}-b_{1}}{\varphi \Delta r-2\left(b_{1}-c_{1}\right)}>1, F_{1}^{\prime}(1)<0, p^{*}=1$ is evolutionary stable strategy, therefore, whatever strategy is carried out, Internet finance are always inclined to choose cooperation with commercial banks. The phase diagram is as follows:

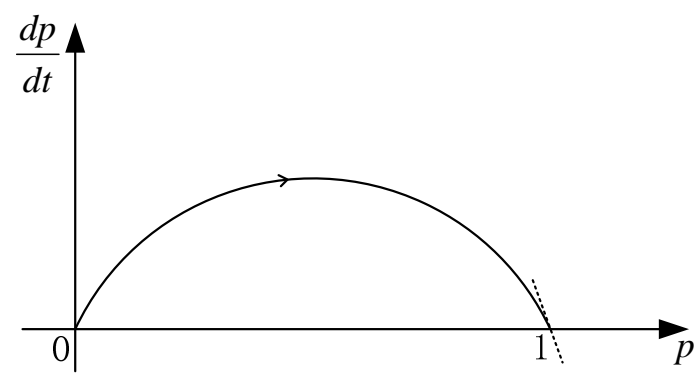

Fig.4 $\frac{c_{1}-b_{1}}{\varphi \Delta r-2\left(b_{1}-c_{1}\right)}>1$ phase diagram

(5) When $\varphi \Delta r>2\left(b_{1}-c_{1}\right)$, namely double net earnings of Internet finance in cooperation with a third party is less than earnings in cooperation with commercial Banks, at this time 
$\frac{c_{1}-b_{1}}{\varphi \Delta r-2\left(b_{1}-c_{1}\right)}<0$, there is always $F_{1}^{\prime}(1)<0, p^{*}=1$ is the evolutionary stable strategy, therefore, whatever commercial banks take strategy, Internet finance are always inclined to choose cooperation with commercial banks. The phase diagram is as follows:

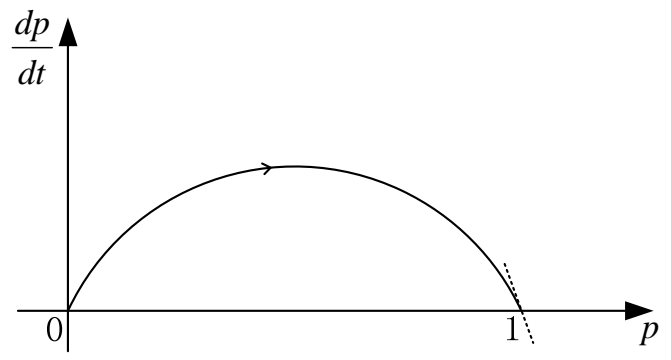

Fig.5 $\frac{c_{1}-b_{1}}{\varphi \Delta r-2\left(b_{1}-c_{1}\right)}<0$ phase diagram

\section{Conclusion}

Under the condition that Internet finance and commercial banks both have limited rationality, Internet finance will cooperate with commercial banks in most cases, only when the probability of commercial banks choosing cooperation with Internet financial is less than a certain value, the Internet finance will "feel" the probability of cooperation with commercial banks is too small, lack of cooperation sincerity, the Internet finance won't cooperate with commercial banks. This request in real life, if the commercial banks want to cooperate with Internet finance, it is necessary to show the sincerity, or make Internet finance feels cooperation with commercial banks at least is a big probability event; otherwise, the Internet finance will take the competition strategy.

\section{References}

[1]Arvind Ashta. An analysis of European online micro-lending websites [J]. Innovative Marketing, Volume 6, Issue 2, 2010.3.

[2]Berger.S and Gleisner F. Emergence of Financial Intermediaries on Electronic Markets: The Case of Online P2P Lending [D]. Working Paper, University of Frankfurt, 2008.

[3] David C. Chou、Amy Y. Chou. A Guide to the Internet Revolution in Banking [J]. Information Systems Management. Volume 17, Issue 2, 2000

[4] Godfrey,B. Lakshminarayanan,K. Load balancing in dynamic structured P2P system[J].Twenty-third Annual Joint Conference of the IEEE Computer and Communications

Societies Volume:4 ,INFOCOM 2004.

[5] Gonzalez L, Komarova Y, Kabadayi S, etal. When Can a Photo Increase Credit?: The Impact of Lender and Borrower Profiles in Online P2P Loans[J]. 2012.

[6] Hulme M K, Wright C. Internet based social lending: Past, present and future[J]. Social Futures Observatory, 2006, 11. 